\title{
AS NÃO-QUALIDADES DE MANUEL DE FREITAS: UMA LEITURA DE “CARPE DIEM”
}

Ana Beatriz Affonso Penna*

RESUMO: Este artigo intenta desconstruir a oposição entre autor "artífice" e autor "possesso" como critério avaliativo para a obra do poeta português contemporâneo Manuel de Freitas através da análise do poema "Carpe Diem", do livro Beau Séjour, de 2003.

PALAVRAS-CHAVE: Manuel de Freitas; poesia contemporânea; valor.
* anabeatriz.a.penna@gmail.com

Mestre em Estudos de Literatura pela Universidade ederal Fluminense e auxiliar docente na

EmoryUniversity.

ABSTRACT: This article intends to deconstruct the opposition between "artificer" writer and "possessed" writer as criteria to evaluate the work of the Portuguese contemporary poet Manuel de Freitas by the analysis of the poem "Carpe Diem", from Beau Séjour, a book published in 2003.

KEYWORDS: Manuel de Freitas; contemporary poetry; value. 
Portugal, 2002. Uma antologia de nove jovens autores contemporâneos instaura um embate no panorama da poesia portuguesa mais recente. Poetas sem qualidades,que é apresentada aos leitores pelo prefácio de Manuel de Freitas, "O tempo dos puetas", propõe com ironia e certa agressividade - que tanto fazem lembrar alguns manifestos modernistas, já tão afastados de nosso presente - a articulação de uma diferenciada dicção líricaem contexto português.

"A um tempo sem qualidades, como aquele em que vivemos, seria no mínimo legítimo exigir poetas sem qualidades" (FREITAS, 2002:9) - anuncia Freitas na sentença de abertura do prefácio. Preocupado em defender um compromisso da lírica com a sociedade, Manuel de Freitas admite a poesia enquanto uma realidade histórica (FREITAS 2002:14), a qual demanda dos poetas uma responsabilidade estética com o seu tempo. Contra ao que chama de "culturalismo autossuficiente"(FREITAS, 2002:13), do qual acusa o renomado poeta Nuno Júdice, Freitas propõe uma poesia que manifesta "força - ou admirável fraqueza - onde outros apenas conseguem ter forma ou uma estrutura anémica (FREITAS, 2002:13).

"O tempo dos puetas", em declarado combate a um fazer poético que exibe um "ostensivo manejo" de 'qualidades' (FREITAS, 2002:14), ergue-se em oposição a uma prática lírica que tem sua principal matriz no que se convencionou chamar de geração de 61. Contra o poeta ourives de barro que "quase torna palpável o esforço" (FREITAS, 2002: 13) com que elabora o artifício, "pensando certamente num público alargável ao seu génio" (FREITAS, 2002: 13), Manue de Freitas prefere uma poesia em que a articulação do poema enquanto "experiência emocional do mundo" (MARTELO, 2003:46) prevaleça sobre um determinado modo de labor formal que busca uma manifesta expressão depurada e não discursiva. Ao recuperar os nomes de António José Forte e Joaquim Manuel Magalhães e propor uma nova recepção de poetas já consagrados pela crítica, como é o caso de Herberto Helder, o poeta escolhe uma tradição outra, na qual ancora práticas poéticas que parecem propor um novo regime de valor para a poesia.

Como já esperado, a reação de parte da crítica a esse programa poético não tardou por vir à tona. A estreita aproximação de sua poesia com a prosa e o discurso banal do cotidiano, rendeu a Manuel de Freitas, como aospoetas sem qualidades, enquanto um possível grupo, a insinuação de que esses estivessem a realizar uma lírica pobre, cuja linguagem poética careceria de um maior investimento imagético assim como sintático. A busca pela ausência de qualidades defendida no prefácio "O tempo dos puetas", quando encarada como um processo de precarização da linguagem poética, encontra 
1. A poesia da década de 60 foi marcada pela publicação do volume Poesia 61, conjunto no qual se vê o surgimento de uma tendência poética comum que representa uma virada na poesia portuguesa do século XX.

2. Este volume da Revista Relâmpago abriu-se à geração mais recente da poesia portuguesa. Seus ensaios de abertura foram dedicados a dar uma imagem da poesia mais jovem que hoje se escreve em Portugal e a discutir sobre a possível existência de uma "nova" poesia portuguesa. engajados combatentes que visam conservar determinadas maneiras de fazer e compartilhar poesia.

Gastão Cruz, poeta da década de $60^{1}$, em seu artigo "Nova poesia e poesia nova”,publicado no décimo segundo número da Revista Relâmpago ${ }^{2}$, ocupa-se majoritariamente em discutir as propostas para a poesia contemporânea apresentadas em "O tempo dos puetas", assim como a obra dos autores da antologia sob a luz do prefácio. Examinando as críticas de Freitas, Gastão considera o programa dos poetas sem qualidades como uma pretensa nova poesia de "marginalidade de papelão" (CRUZ, 2003:35) que, em sua visão, muitas vezes não é, verdadeiramente, mais do que um "descritivismo morno, a observação rasteira do que o cerca [...], a má (ou menos má...) prosa disfarçada de poema" (CRUZ, 2003:31). Sobre os ataques de Freitas, como, por exemplo, ao poeta Nuno Júdice, Gastão considera-os "sem qualquer fundamentação ou desenvolvimento de pontos de vista” (CRUZ, 2003:31) não passando de execuções sumárias sem ressalvas críticas (CRUZ, 2003:31), sem contarem, assim, de menor consistência. Já a defesa de uma lírica que preza a comunicação como um dos seus grandes valores é vista como um modo de conduzir "ao culto da mediocridade, da banalidade, à ausência de risco, ao recuo perante qualquer veleidade de invenção verbal, em suma, a uma poesia (realmente) 'sem qualidades" (CRUZ, 2003:32)
Conforme se observa, não são poucas as objeções do representante da Poesia 61aos poetas sem qualidades e, como consequência, à atividade poética e crítica de Manuel de Freitas. Mas, a fim de objetivar uma análise, poder-se-ia sintetizá-las em alguns pontos. São eles: a desvalorização da poesia enquanto labor, a radicalidade crítica sem embasamento, o definhamento da linguagem poética em prol da comunicação direta com o leitor, a ausência de uma fundamental ideia metafísica e de um profundo conceito de vida (CRUZ, 2003:34) e a encenação de uma marginalidade. Começo por tratar da desvalorização da poesia enquanto labor.

Em Teoria da Literatura, Vítor Manuel de Aguiar e Silva discorre em um dos seus capítulos sobre o problema da criação poética. Ao abordar a questão da polaridade entre autor "possesso" e autor "artífice", Aguiar e Silva indica que "não estamos em face de uma constante que actueabstracta e descarnadamente, mas perante duas atitudes estéticas com motivações e naturezas diversas" (SILVA, 1988:163) que "significam a constância de determinados valores nas figurações complexas e historicamente variáveis que o poeta reveste através do tempo" (SILVA, 1988:163). O autor "possesso", afastando-se da atividade racional, de regras e de modelos, seria aquele que encontra na inspiração e na espontaneidade do gênio criador as bases do seu fazer poético (SILVA, 1988:169). Já o autor “artífice”, o qual crê na poesia enquanto 
3. Distinção de tensões essa que Martelo parece retirar da Magalhães: “Contra a necessá na altura, rarçã̃o docessá, na altura, rarefaç̧áo do sentimento, do enunciado e do imaginário, surge na poesia mais recente um impeto renovado de se contar, de assumir, por máscara ou diretamente, um discurso cuja tensão è menos verbal do que explicitamente 1981:258). resultado da estreita dependência das faculdades intelectuais, subestimaria o papel de experiências extáticas, que não se relacionam com a atividade consciente, para a prática poética (SILVA, 1988:169).

De modo menos polarizado, Rosa Maria Martelo, em seu artigo a respeito dos poetas sem qualidades, ao mencionar a valorização da tensão emocional do poema em detrimento de uma tensão essencialmente verbal ${ }^{3}$ como característica da "poesia sem qualidades" (MARTELO, 2003: 48), recupera, de certa maneira, uma dicotomia presente na descrição autor "possesso" e autor "artífice", embora deixe claro que está longe das intenções da "poesia sem qualidades" resgatar a aura do poeta romântico. Tal posicionamento vem a solidificar-se com as próprias colocações de Freitas em "O tempo dos puetas", em que uma aproximação perante o tempo e o mundo, descrita em termos de manifestação de força ou fraqueza, é preferida a uma poesia de cunho formal, porém sem vitalidade (FREITAS, 2002:14). No entanto, seria o constante embate entre autor "possesso", ou tensão emocional, e auto "artífice", ou tensão verbal, realmente o caso dos poetas sem qualidades? Creio que não.

Tanto a imagem do autor "possesso" quanto a imagem do autor "artífice" são posturas já sacralizadas da prática poética. Ambas partilham de uma aura incompatível para poetas que "não são muita coisa" (FREITAS, 2002:14), como já aponta Rosa Martelo (MARTELO, 2003:46). De certo, a ideia de um dinamismo inconsciente capaz de gerar o sublime, assim como a do estudo e do labor, possuem demasiadas qualidades para que se encaixem na programática de "O tempo dos puetas". E ainda que a figura do gênio apareça para descrever e simultaneamente escusar Herberto Helder, essa, quando aplicada para pensar a poética dos "sem qualidades", apenas soa como um excesso deselegante - um anacronismo.

Mas se não se trata de poetas que reivindicam para si uma linguagem fruto da emoção e da inspiração, nem do artifício, o que afinal quer a poesia de "O tempo dos puetas" além de uma aparente pauperização da linguagem poética? A começar, como postula Aguiar e Silva, a criação poética não se pode resolver através de uma redução a uma forma simplista e rígida, tornando-se necessário reconhecer que um bom poema ultrapassa a depuração formal, como também não pode existir senão enquanto trabalho de linguagem (SILVA, 1988:202.). De modo que a tensão verbal de um poema nada vale se não acompanhada de uma tensão emocional e vice e versa. Poemas ditos de um alto grau de depuração formal, como "O poema ensina a cair", de Luiza Neto Jorge, ou "Soluço”, de Gastão Cruz, não parecem servir de exemplo para atestar o predomínio de uma tensão
EM TESE
BELO HORIZONTE
v. 19
N. 2
AG0.-OUT. 2013
PENNA. As não-qualidades de Manuel de Freitas: uma leitura de "Carpe Diem" P. 56-70 
verbal sobre uma emocional, uma vez que as duas tensões aparentam estar indissociáveis. Já Edgar Allan Poe, que surge dentro do romantismo norte-americano, em seu texto "A filosofia da composição", desvela de maneira metódica o processo de criação de um dos seus poemas de maior tensão emocional - "O corvo" - gerando a desconfiança de que não há em um bom poema grande tensão emocional sem igua tensão verbal, nem grande tensão verbal sem igual tensão emocional.

Desse modo, o que parece estar em jogo no que se denomina tensão emocional no artigo de Martelo é justamente a questão da subjetividade, sendo a poesia de expressão emocional aquela de tradicional enunciação de um eulírico, claramente marcado no poema, e não o caso de uma poesia de primazia do sentimento - já em uma acepção romântica. A revalorização da enunciação lírica somada à figuração de certa experiência individual e cotidiana de mundo traria aos "sem qualidades" uma tensão cuja nomeada emotividade, no artigo de Martelo, parece identificar-se com uma visão de emoção enquanto uma articulação mais direta de um eulírico ao par poema-mundo e não com a noção de força/ fraqueza apresentada por Freitas, nem com a expressão de certo transbordamento sentimental. Pois, ainda que a poesia de um Manuel de Freitas seja altamente afetiva nas dedicatórias e referências aos amigos, família e amores, assim como intensa em seu confronto eu lírico/poema/mundo ${ }^{4}$, existe, com regularidade, em sua poética uma rarefação retórica e imagética a qual não permite um transbordamento sentimental ou uma manifestação de força senão em certos momentos chave do poema - momentos em que se observa uma maior densidade e tensão retórica e imagética. Tais momentos, os quais coincidem especialmente com os versos finais, como assinala Joaquim Manuel Magalhães ao falar da poesia de Rui Pires Cabral, apontam para "[...] a precisa maestria com que cada poema cresce para o seu fim" (MAGALHÃES 1999:278). De forma que se observa em Manuel de Freitas, como em Rui Pires, um trabalho para a construção de uma organicidade textual, a qual "exige uma chave final que faça crescer o ritmo das declarações e encerre o poema com qualidade conseguida" (MAGALHÃES, 1999:278).

Fruto de vigilância e labor, tal rarefação retórica e imagética, como afirma Pedro Eiras, "é um trabalho de renúncia à auréola, porque nenhuma auréola se perde de uma vez por todas" (EIRAS, 2011:52). Em embate ao processo constante de recomposição aurática das artes (GUERREIRO apud EIRAS, 2011:52), ergue-se a necessidade de uma poesiaà contramão de tantas qualidades que adornam a linguagem poética, embotando-a. Já não mais se trata de "limar as arestas que a vida deveras tem" (FREITAS, 2002:14), pois o excesso da vida, ainda que "baixo e deselegante" (FREITAS, 2001:11), é
4. Por confronto eulírico/poema/ mundo, entendo o choque entre uma determinada figuração de "eu" com uma específica figuração de mundo que só pode acontecer através do poema, ou seja, através de uma criação de linguagem, confrontando-se assim também o lugar dessa criação.

\begin{tabular}{|c|c|c|c|c|c|}
\hline EM TESE & BELO HORIZONTE & v. 19 & N. 2 & AG0.-OUT. 2013 & PENNA. As não-qualidades de Manuel de Freitas: uma leitura de "Carpe Diem" \\
\hline
\end{tabular}


agora "uma maneira de dizer ausência" (FREITAS, 2003:55). Importa é limar as auréolas do poema e da vida, em busca de uma linguagem poética que possa dizer seu tempo: fazer sentido. Assim, a prática adotada por Freitas de alternar picos imagéticos e retóricos nos poemas com pequenas descrições e narrativas prosaicas mostra-se, dessa maneira, um trabalho de linguagem que dá forma a uma concepção de poesia que procura, na ausência de qualidades de um tempo e espaço, a emersão do poético, mesmo enquanto resto - o qual, ainda que ingerido, recusa-se a ser completamente absorvido por uma lógica reificadora. Vejamos o poema "Carpe Diem"do livro BeauSéjour:

O fantasma de um fantasma

de um fantasma. Uma

tautologia escusada

para quem achou sempre

que nunca existiu.

Repara no teu dia:

entraste na taberna

da Zulmira, de frente

para o azul forte das paredes.

Ela não te reconheceu,

hesitava entre o jornal

a vassoura, a televisão.
Em directo de Coimbra, da

Sé Nova, o horror vinha matar

o fim da manhã, neste país.

Acontece. Aquela ginja, a mulher

que se dispunha a segurá-la

traziam-te por filosofia de bolso

a resignação. Mais tarde,

os relâmpagos iluminaram-te

o caminho, como se houvesse

caminho. A viúva do Hortelão

também não te reconheceu.

E é isso: começas a perceber

que não existes, doutra mais

funda maneira - sem resposta.

Há um copo, ao teu lado, e um corpo

que não fotografará o desespero.

As mãos - procurando a sombra.

O excesso, agora, é uma maneira

de dizer ausência, o azul caído

em meados de Setembro.

(FREITAS, 2001:54-55)

O poema, o qual se divide em quatro estrofes, inicia-se com algo semelhante a uma proposição, em que o sujeito 
5. Grifos meus. lírico expõe em linhas gerais uma espécie de tema a ser desenvolvido. "O fantasma de um fantasma / de um fantasma" - construção sarcástica assumidamente tautológica - multiplicar-se-ia ao infinito sem nunca chegar a um elemento que apresentasse uma saída à repetição da lógica interna do enunciado. Fruto de um jogo trivialde retórica, que já revela as suas não qualidades imediatamente após sua enunciação ("Uma / tautologia escusada"), a figura dá aos leitores a sensação de aprisionamento a uma situação débil/ medíocre, mas impossível de ruptura. Pois ainda que o jogo de espelhos seja revelado enquanto reles construção, isso não desfaz a reflexão contínua da imagem em novos espelhos, apenas incitando a angústia dos que reconhecem o mecanismo de funcionamento.

O sujeito, então preso, como em maldição, à impossibilidade de constituir-se senão precariamente, manifesta, pela aproximação de palavras de sentidos opostos ("para quem achou sempre/ que nunca ${ }^{5}$ existiu"), uma zona de indiferenciação entre sim e não. De modo que o "sempre", ao confirmar o valor de "nunca", perde seu traço distintivo de positividade para transformar-se também em negatividade - tal como o fantasma, o qual apesar de ainda ser capaz de uma sobrevida, pertence à morte. Ambos contínuos que não admitem movimentos de disrupção, "sempre" e "nunca" passam a equivaler-se em um cenário de eterna ausência que atualiza o dilema hamletiano - no qual tudo ou nada (ser ou não ser) torna-se tudo é nada. Mas deixemos os fantasmas shakespearianos para concentrar-nos no fantasma de Freitas.

A segunda e terceira estrofe são majoritariamente uma pequena narrativa em que o sujeito desenvolve o mote apresentado na primeira estrofe do poema. Através da descrição de episódios mínimos, a voz do poema relata o não reconhecimento de sua pessoa por parte de personagens que pertenciam ao seu passado. Mas ainda nas partes narrativas, o leitor depara-se com algumas metáforas, como "[...] o horror vinha matar / o fim da manhã, neste país." e "Mais tarde, / os relâmpagos ${ }^{6}$ iluminaram-te/ o caminho", em que o comparante substitui o comparado. Observa-se também que, nos versos da segunda e terceira estrofe, a detenção descritiva sobre o lugar e outras particularidades da cena sobrepõe-se à ação narrativa para configurar uma espécie de Zeitgeist poética. Zulmira que "hesitava entre o jornal/ a vassoura, a televisão" está perdida entre poderosos dispositivos alienadores. Mais do que meros objetos banais, "o jornal/ a vassoura, a televisão" expressam uma relação de contiguidade, sendo utilizados por sua representação. Ao trabalho e à mídia, acrescenta-se o discurso religioso, também midiatizado, que interrompe violentamente a cena: "Em directo de Coimbra, da/ Sé Nova, o horror vinha matar/o fim da manhã, neste país.". 
A seção narrativa do poema, que é introduzida na segunda estrofe com um verbo no imperativo, configurando-se enquanto uma orientação para a segunda pessoa do singular em um futuro imediato - "Repara no teu dia:" - aponta como locutor o próprio sujeito poético, o que enfatiza a condição de aprisionamento do indivíduo em si. Após nove versos em tempo passado que seguem a orientação, a primeira sentença da terceira estrofe apresenta um tempo presente que funciona como comentário do sujeito lírico "Acontece ${ }^{7}$. Aquela ginja, a mulher/ que se dispunha a segurá-la/ traziam-te por filosofia de bolso/ a resignação [...]”. Tal como o imperativo "repara", o presente do indicativo "acontece" evidencia um excesso de consciência dos fatos sucedidos no passado que descamba em uma espécie de cinismo em relação às próprias memórias. Recuperado no nono verso da terceira estrofe, o tempo presente fechará a narrativa, retomando quase didaticamente a proposição da estrofe inicial: "E é isso: começas a perceber/ que não existes, doutra mais/ funda maneira sem resposta".

Desse modo, observa-se que o poema necessita ir a tabernas, buscar na narrativa prosaica a matéria de constituição subjetiva. Como aponta Pedro Eiras, "a multidão, os pobres, as ruas, o trânsito não são um simples conceito neutro, descartável" (EIRAS, 2011:174), o fundo circunstancial do poema é a subjetividade fora do sujeito, constituindo-se dessa maneira através de um espaço exterior, plural, coletivo e também político (EIRAS, 2011:174). A tautologia anunciada nos versos iniciais, referente à figura "O fantasma de um fantasma / de um fantasma”, em verdade, parece ser também uma menção ao modo de escrita do poema. É preciso dizer a mesma coisa em termos diferentes: somente quando mergulha sua aflição nas dores cotidianas, compondo o que considera o espírito de sua época, o sujeito consegue dar plena expressão ao mote do poema. E talvez seja isso a escrita poética, ou ao menos a poesia de Freitas: variações de uma obsessão, "maneira frágil de desobedecer à morte" (FREITAS, 2010:19).

Mas se há a escolha estética por deslocar a subjetividade para fora do sujeito no poema e escrever a cidade, as tabernas, os mercados, há também a constatação do constrangimento dessa espécie de paisagem sobre os indivíduos, surgindo da a necessidade de dizer os campos de força presentes em uma realidade sócio-histórica para a formação e/ ou expressão de uma subjetividade:

Não há fundo e tudo é fundo. Os homens são moldados pelo dia esmagador, pela noite repousante, forças maiores. Reagem, como joguetes: uns tornam-se feras, outros finalmente descansam [...]. O mesmo fundo circunstancial - a mesma 
noite, o mesmo dia - governa, decide, manipula o destino de todos: obedecem igualmente [...]. (EIRAS, 2011:178)

No entanto, ainda que a paisagem seja uma estrutura produtora de modos de subjetividade, essa é uma construção sociocultural que exige uma atividade constituinte de um sujeito que a organize de acordo com sua percepção, conforme afirma o ensaísta Michel Collot (COLLOT, 1997:211). Já não se trata mais de uma via de mão única, como era o caso da concepção romântica, em que a paisagem era subordinadora do estado de alma do indivíduo, agora há o entendimento do papel do sujeito para a inscrição de uma paisagem através de seu olhar. De forma que não existe uma paisagem sem a apreensão sensível de um eu no mundo, portanto, sujeito a diversos condicionamentos de sua realidade e a modelos perceptivos: "Le paysage, ce n'est pas le pays réel, c'est lepays perçu du point de vie d'um sujet. Il n'appartient pas à la réalité objective, mais à une perception toujours irréductiblement subjective" (COLLOT, 1997:193).

Ainda a falar dos usos dos tempos verbais no poema, ressalta-se a ocorrência de dois passados inscritos entre dois esquecimentos. O primeiro passado, mais recente, é o do sujeito que retorna à taberna da juventude e já não mais encontra o reconhecimento das personagens que habitavam sua vida. Sem pares que se recordem de sua pessoa e, por tanto, validem seu passado, o eu lírico tem sua identidade ameaçada pelo esquecimento. Esse passado, contido entre os comentários do sujeito no presente, dá lugar na terceira estrofe a outro passado mais remoto. Em uma espécie de flashback, o eu do poema retoma as memórias de sua vivência naquele local, as quais irrompem após a aceitação de seu esquecimento na oração inicial da terceira estrofe. Porém, a digressão no passado de sua juventude não se alonga, sendo logo sustada por um outro não reconhecimento: "[...] A viúva do Hortelão /também não te reconheceu.". Chamado à realidade pelo impacto do passado mais recente, o sujeito recorre mais uma vez ao presente, encerrando a narrativa com um comentário sintetizador, como já mencionamos anteriormente. No entanto, interessa atentar para a cena que segue ao comentário, após constatar-se a ausência de resposta ao dilema tautológico: "Há um copo, ao teu lado, e um corpo/ que não fotografará o desespero./ As mãos - procurando a sombra".

A cena, localizada no presente, passa-se provavelmente na mesma taberna que ainda pouco era cenário dos desencontros do sujeito. Distanciando-se apenas ligeiramente de um passado recente, a disposição de planos é uma descrição instantânea de um agora que prontamente será engolido pelo tempo, tornando-se também passado. É majoritariamente a partir do passado que os indivíduos podem estabelecer sua história e um processo de subjetivação, pois o futuro 
enquanto projeção e o presente na sua brevidade não oferecem às pessoas propriedades suficientes para a reflexão de sua condição de sujeitos. Assim, a escolha pela existência de diferentes tempos cronológicos no poema - a de um passado distante que está a se perder pelo seu não reconhecimento em um passado recente e a de um presente que está quase a ser devorado pelo passado - é sintomática da aflição do sujeito quanto ao apagamento do eu em decorrência do movimento dos tempos. Sem poder-se apoiar no passado para ser no presente, o sujeito tampouco confia no futuro, já que as promessas do passado não se cumpriram - "E só lhe restam / agora o tempo, o nada, a morte / e as palavras que não sabem dizê-los.” (FREITAS, 2003:2). “Carpe Diem”, lem dos adeptos de um hedonismo cego como também daqueles que buscam saborear o dia em suas possibilidades, ironicamente, converte-se em uma maldição: nada existe para além de um penoso presente e uma experiência passada elíptica impossível de reconstituição, a qual Eduardo Prado Coelho identifica como marca na configuração de uma melancolia característica da poesia portuguesa recente: "É da lenta passagem de um fragmento presente para um fragmento que se esbate no seu próprio estatuto lacunar que emerge esse sentimento de perda de que se vai tecer a melancolia poética do final do século" (COELHO, 2003:12).
Ser desterrado, despojado de sua identidade habitante-lugar, o sujeito lírico de "Carpe Diem" parece assinalar a precariedade e finitude a que todas as existências estão subjugadas. A escrita da experiência e, consequentemente da memória, inscrita na imagem de "As mãos - procurando a sombra", sugere a tentativa de uma resistência: embora já não mais exista a utopia da claridade plena, a sombra avista-se ainda como possibilidade. Apesar de em um tom menor, faz-se necessário procurar um dizer que intente encontrar uma interposição entre a utopia da palavra poética e a descrença, sendo assim capaz de salvar o poema da repleta escuridão. Em uma era em que a imagem físico-matemática da velocidade apresenta-se como um emblema, o poema propõe uma dobra à consumação pelo tempo. Como afirma o filósofo e urbanista Paul Virilio, "quando você vai depressa demais, você é inteiramente despojado de si mesmo, torna-se totalmente alienado. É possível, portanto, uma ditadura do movimento." (VIRILIO, 1984:65). Desse modo, a escrita poética, ao cristalizar o fluxo dos sentidos em uma imagem, reter um breve instante, arrancar da morte o afeto que permanece, age de forma a solidificar o processo de subjetivação do eu, a interromper a linha reta temporal. Pois em tempos em que "o efeito de real parece suplantar a realidade imediata” (VIRILIO, 1993:18), a presença de uma forte marcação do sujeito da enunciação e do testemunho em poesia parece 
indicar uma reivindicação do indivíduo pela valorização e reconhecimento do lugar de sua subjetividade.

Um dos trechos mais imageticamente ricos do poema, os versos finais da terceira estrofe estão dispostos como uma cena cinematográfica, fixando-se em uma unidade espaço-temporal. Seu primeiro plano focaliza a disposição de dois elementos: um copo e um corpo. Aparentemente captado por um ângulo superior, a do olhar do sujeito sobre uma provável mesa / balcão, o plano, que já possui uma proporção de enquadramento minimalista, ao ser interrompido por outro plano, é sucedido por um fechamento de enquadramento ainda menor sobre as mãos: parte representante do todo ("um corpo") como também sinal da coisa significada (a escrita). Copo e corpo - palavras que podem ser utilizadas metonimicamente enquanto contentores pelo conteúdo, se acaso houver um conteúdo para o corpo - aproximam-se também por suas semelhanças fônicas. Dois pesos sobre uma superfície, o poema aparenta sugerir que as diferenças entre "corpo" e "copo" não são tão grandes, sendo necessário rebaixar o corpo à matéria e o sujeito ao corpo. Mas diferentes de copos e corpos, o desespero não é fotografável, pois não se constitui em partes de matéria. A esse algo além não reproduzível pelo corpo em uma imagem tão precisa quanto a da tecnologia fotográfica, resta a inscrição na escrita pelo investimento corporal - as mãos. Um sujeito necessariamente de carne: para Freitas, não há metafísica suficiente para escapar à matéria.

A respeito das escolhas sonoras do poema, como perceptível na análise da cena anterior, comprova-se um trabalho de seleção de unidades fônicas para a expressão de sentidos na poesia de MF. Mas o que dizer da segunda e a terceira estrofe de "Carpe Diem", até o seu vigésimo sexto verso? Marcadamente mais descritivas e narrativas, elas apresentam um discurso mais próximo da linguagem tradicional, encarregada de transmitir uma mensagem voltada para a comunicação. No entanto, um olhar mais atento observa particularidades importantes para a compreensão do poema e do fazer poético de Manuel de Freitas. Tomemos como exemplo os quatro versos iniciais da segunda estrofe: "Repara no teu dia:/ entraste na taberna/ da Zulmira, de frente/ para o azul forte das paredes".

Observa-se nos versos anteriores a prevalência de consoantes oclusivas surdas e sonoras ( $\mathrm{t}$, b e d), as quais são explosivas. Fonemas produzidos quando o ar que vem dos pulmões encontra um obstáculo, o que resulta num tipo de estouro, as oclusivas sugerem uma ideia de choque (CANDIDO, 2006:55). O grafema "r", cujas variações fonéticas presentes no poema parecem exprimir um ruído seco repetido (CANDIDO, 2006:56), é também tão recorrente quanto às oclusivas. Já nos versos finais, há a maior 
8. As sequências silábicas que se repetem ou que apresentam uma grande relação de semelhança estão marcadas em cores:

Repara no teu dia: Entrastenataberna DaZulmira, defrente para o azul fortedas paredes ocorrência das fricativas z, s e f, sendo as consoantes "f" seguidas da vibrante " $r$ " e as consoantes " $z$ " seguidas da voga "u". Em geral, os pontos de articulação coincidem: o articulador ativo é a lâmina da língua e o passivo os alvéolos (caso de "r", "t", "d", "s" e "z"). Ao longo dos versos, ocorre também a repetição de sequências silábicas iguais ou ligeiramente diferentes, sendo vinte e quatro as sílabas que se repetem para seis que não. Quanto às vogais, a maior incidência é dos grafemas "a" e "e", os quais ainda que naturalmente mais usados no português, em proporção à ocorrência das demais vogais, podem ser considerados em uma média acima da sua usual manifestação: são catorze "a" e onze "e" para três "o", três "i" e três "u".

Elaborar uma interpretação a respeito da ocorrência das unidades sonoras dos versos acima, relacionando-as a um sentido expresso no texto, parece-me uma tarefa demasiadamente ousada com grandes riscos de incorrer em apenas uma impressão pessoal. Poder-se-ia dizer que a recorrência das oclusivas expressaria a noção de certa violência - aberta - pelo uso da vogal "a”, e que o uso das vibrantes, ao sugerir um som desarmônico seco, potencializaria a violência das oclusivas, sendo, enquanto um ruído, um obstáculo para a fluidez. Já as fricativas, que tradicionalmente são ligadas à ideia de sopro, sussurro, deslizamento e frêmito, somadas à aparição do fonema [e], poderiam representar uma sensação de estreitamento, uma vez que a fricção das consoantes é produzida pelo aperto do ar e o fonema [e] possui um som mais fechado. Tal estreitamento, interrompendo a violência aberta das consoantes explosivas, elevaria a tensão poética por representar uma contenção a uma explosão que deseja realizar-se sem impedimentos. Assim, a descrição que antecede o não reconhecimento do sujeito pela dona da taberna seria imbuída de um suspense, uma violência tensionada pela contenção das fricativas que apenas se liberta com o verso "Ela não te reconheceu", em que há a predominância de vogais fechadas, consideradas sombrias (CANDIDO, 2006:56)

No entanto, como já mencionado, considerações de estilística fônica podem ser uma leitura arriscada, importando mesmo é apontar a ocorrência de uma regularidade no uso de determinadas unidades sonoras para fins expressivos. $\mathrm{O}$ que interessa é evidenciar que existe um trabalho poético de linguagem na poesia de Manuel Freitas até em seus momentos de maior aproximação com o discurso trivial. Sendo também de valia salientar a relação de ritmo que se estabelece nos versos analisados para além da recorrência de sequência silábicas iguais ou similares e a repetição de certos fonemas. Se ditos de maneira natural, sem destacar sílaba por sílaba, os versos iniciais da segunda estrofe poderiam ser marcados por duas sílabas fortes que se elevam sobre as demais, constituindo-se assim uma regularidade rítmica. Contudo, 
9. Grifos meus.

há como exceção o quarto verso, o qual, mais longo, possui três sílabas fortes: "Repara no teu dia:/ entraste na taberna/ da Zulmira, de frente/ para o azulforte das paredes" ${ }^{\text {. }}$

O quarto verso, que naturalmente já se destaca dos seus anteriores por sua extensão, apresenta uma espécie de meio tônico e gráfico marcado pelo adjetivo "forte". O termo "forte", cujo significado coincide com sua posição de tonicidade no poema, pesa sobre a leitura do verso e incide sua força sobre o substantivo ao qual se refere. "Azul”, que também ocupa uma posição tônica no verso pela sílaba "zul”, é palavra retomada na última estrofe do poema, onde se vê esboçar algo que semelha a uma proposição de arte poética: "O excesso, agora, é uma maneira/ de dizer ausência, o azul caído/ em meados de Setembro".

Se, na primeira ocorrência do azul no poema, o adjetivo é "forte", na segunda, torna-se "caído", recuperando-se o imaginário de queda ocidental. Azul, cor historicamente atrelada à liberdade - lembremo-nos, por exemplo, da bandeira francesa - está, em sua última aparição no poema, no lugar de céu - espaço aberto, como sublime, mas, concomitantemente, representativo de uma escatologia cristã. De modo que a expressão "azul caído", ao mesmo tempo em que recupera a noção de paraíso, abertura e sublime através de uma sensação visual, condiciona-a a uma ideia de danação, fechamento e impossibilidade. $\mathrm{O}$ azul, apenas forte quando em tabernas como a de Zulmira, só pode existir enquanto potência emparedada. Tal qual a poesia, sua força está circunscrita a espaços restritos. Lugar de representação de um submundo urbano em contexto europeu, portanto em uma vivência alternativa à normalidade diurna da moral do trabalho e da família - "o azul forte" está distante de qualquer espaço institucional. Sua presença em uma parede de taberna ao mesmo tempo em que sugere uma posição de marginalidade, desvela uma possível inadequação. A força do azu quando compreendida enquanto exagero/ deselegância, soa como algo grotesco por seu descabimento: um azul deformado por uma violação - um simulacro celeste.

Mas fica a pergunta: como dizer "o azul caído / em meados de setembro?" Como dizer a ausência? Pares, porém, paradoxais, excesso e ausência, tais como "sempre" e "nunca", são aproximados semanticamente no poema. Uma abundância carente ou uma carência abundante: o excesso pode agora dizer a ausência. Em oposição a uma poética de rarefação do "eu", do planejamento arquitetônico do poema enquanto selo de qualidade, Freitas parece insistir em um transbordamento. Há no poema um aparente excesso de literalidade que se recusa à fácil assimilação por um conceito tradicional de poesia e que, ainda assim, teima em fazer-se em versos. Porém, por trás da aparente trivialidade do discurso, observa-se a necessidade de procurar excessivamente uma forma de expressão 
que possa aproximar-se do não-dito da linguagem prosaica, da ausência: um "sublime irrepresentável" (COELHO, 2003:12), nas palavras de Eduardo Prado Coelho.

Assim, diferente do que entende Gastão Cruz, a poesia "sem qualidades" de Manuel de Freitas, como observável pela análise do poema "Carpe Diem", não propõe um abandono do labor, forjando de poesia a fala cotidiana. Atenta a aspectos formais, tais como a seleção fônica, verbal e rítmica das palavras, ela procura uma linguagem outra capaz de traduzir uma densidade de pensamento. Preocupada com "a pequena poesia possível nestes tempos de agora" (MAFFEI 2005:166), a poesia de Manuel de Freitasescolhe configurar-se através de um aparente excesso de prosaísmo que fornece sentidos os quais não seriam acessíveis de outra maneira. De modo que existe no fazer poético desse poeta uma intencionalidade conceitual intrinsecamente atrelada a uma configuração formal do poema.

Contudo, que sentidos serão esses? Estaria o leitor apenas diante do "descritivismo morno, a observação rasteira do que o cerca [...]” (CRUZ, 2003:31) sem uma fundamental ideia metafísica (CRUZ, 2003:34)? Um exemplar da pauperização do poético em virtude de um cotidiano massivo? Creio mais uma vez, que essa não seja a resposta. Ao longo da leitura de "Carpe Diem", despontam tópicos que se apresentam como constantes na obra de Freitas. Queda, violência, afeto, violação, escrita, efemeridade, memória, corpo e mortalidade são temas que passam ao longe da ausência de um profundo conceito de vida. Manuel de Freitas, conforme aponta Ida Alves com o poema que encerra seu artigo "Conflito de opiniões na poesia portuguesa: $\mathrm{O}$ esterco e o grito do anjo", não está a falar, naturalmente, apenas de tabernas:

$[\ldots]$

Há um lugar que escreve sobre

a ausência de todos os lugares.

Tonéis de vários tamanhos

onde inscrevi, por distracção,

o único nome verdadeiro.

Estou a falar, naturalmente,

de tabernas.

Mas talvez não seja apenas isso.

(FREITAS, 2005:21)

\section{REFERÊNCIAS}

ALVES, Ida. O conflito de opiniões na poesia portuguesa: o esterco lírico e o grito do anjo. PEDROSA, Celia; ALVES, Ida (Org.). In:__. Subjetividades em devir - estudos de poesia moderna e contemporânea. Rio de Janeiro: 7Letras, 2008. 
CANDIDO, Antonio. O estudo analítico do poema. São Paulo: Associação Editorial Humanitas, 2006.

COELHO, Eduardo Prado. "Não há palavra que cheguem". Público. Lisboa: 24, maio, 2003.

COLLOT, Michel, La notion de paysage dans la critique thématique. In: (dir.). Les enjeux du paysages. Bruxelles: Ousia, 1997

CRUZ, Gastão. Nova poesia e poesia nova.Relâmpago. Lisboa: Fundação Luis Miguel Nava, n. 12, abril, 2003.

EIRAS, Pedro. Um certo pudor tardio. Ensaio sobre os "poetas sem qualidades". Porto: Edições Afrontamento, 2011.

FREITAS, Manuel de. Os Infernos Artificiais. Lisboa: Frenesi. 2001

FREITAS, Manuel de. O tempo dos puetas. Poetas sem Qualidades. Lisboa: Averno. 2002.

FREITAS, Manuel de. BeauSéjour. Lisboa: Assírio \& Alvim. 2003.

FREITAS, Manuel de. A flor dos terramotos. Lisboa: Averno. 2005

FREITAS, Manuel de. A Nova Poesia Portuguesa. Lisboa: Poesia Incompleta. 2010b.

MAFFEI, Luis. O vate de Freitas ou Camões decerto não se importará. Gragoatá. Niterói: EdUFF, 2005, v. 18, p. 307-320.
MAGALHÃES, Joaquim Manuel. Os Dois Crepúsculos, Lisboa: A Regra do Jogo, 1981.

MAGALHÃES, Joaquim Manuel. Rima Pobre. Barcarena: Editoria Presença, 1999.

MARTELO, Rosa Maria.Reencontrar o leitor. Relâmpago. Lisboa: Fundação Luís Miguel Nava, n 12: abril, 2003.

POE, Edgar Allan. The philosophy of composition. In: Matthews, Brander, ed. (1852-1929). Oxford: The Oxford Book of American Essays, 1914. Disponível em: <http://www.bartleby.com/109/11. $\mathrm{html}>$. Acesso em: 10 ago 2011

SILVA, Vítor Manuel de Aguiar. Teoria da Literatura. Coimbra: Livraria Almedina, 1988.

VIRILIO, Paul, O Espaço Crítico. São Paulo: Editora 34, 1993.

VIRILIO, Paul, A Guerra Pura, São Paulo, Brasiliense, 1984 